Article

\title{
Displacing the Gender Binary Through Modes of Dis/Organizing: Sex Toys, Sexuality and Trans Politics
}

\author{
Ludovico V. Virtù \\ Institute for Management Research, Radboud University, 6525 AJ Nijmegen, The Netherlands; E-Mail: vick.virtu@gmail.com
}

Submitted: 13 March 2020 | Accepted: 2 July 2020 | Published: 18 September 2020

\begin{abstract}
Scholars in sexuality and organization studies have highlighted the centrality of sexuality in organizational power and the ways in which sexuality is in/visibilized, controlled, violently exercised, normativized, and/or resisted in organizations. However, there is still little empirical research focusing on social-movement organizations that promote political change in transgender sexual cultures. With this article, I contribute a qualitative case study of a trans and non-binary do-it-yourself (DIY) sex-toy workshop. Drawing on organization, social-movement, and transgender studies, I develop the notion of 'transorganizing' as a specific mode of organizing and ask: How does trans-organizing around sexuality displace the gender binary in the context of a DIY sex-toy workshop? My findings hint at three dis/organizing processes: dis/organizing language, embodiment, and knowledge sharing.
\end{abstract}

\section{Keywords}

dis/organizing; do-it-yourself; gender; organization studies; sex toys; sexuality; social movement studies; trans politics; transgender studies; trans-organizing

\section{Issue}

This article is part of the issue "Trans* Politics: Current Challenges and Contestations" edited by Mieke Verloo (Radboud University, The Netherlands) and Anna van der Vleuten (Radboud University, The Netherlands).

(C) 2020 by the author; licensee Cogitatio (Lisbon, Portugal). This article is licensed under a Creative Commons Attribution 4.0 International License (CC BY).

\section{Introduction}

The sex-toy industry includes both 'business as usual' and proto-feminist businesses (Comella, 2017; Tyler, 2011), both of which reveal sex toys' complex production, resistance, and co-optation processes in a for-profit context. Studies of the sex-toy business focusing on the experiences of women, specifically at in-home sex parties, have shown the degrees of resistance that these environments enable. For the women interviewed by McCaughey and French (2001), for instance, sex toys are empowering against the societal taboo surrounding marginalized sexualities. At the same time, the authors also recognize that sex, sexuality, and the body are implicated in commodification processes, as our social needs depend more and more on the market for satisfaction (Tyler, 2004). From this perspective, sex toys are commodities whose accessibility primarily depends on businesses and the market. Therefore, any empowerment provided within such a capitalized environment might be inscribed in an individualistic consumption model, rather than in the collective critique of traditional/normative discourses of sex, sexuality, and gender so cherished by the women in the McCaughey and French's (2001) study.

This article looks at sex-toy production in a not-forprofit context, which sets itself in opposition to capitalist consumption models, to investigate whether this mode of organizing allows for a collective critique of traditional/normative discourses on sex, sexuality and the body. I analyse a workshop on do-it-yourself (DIY) sex toys at a festival on trans and non-binary culture organized by a trans-led activist group in a mid-sized Northern European city. In this context, trans and non-binary are umbrella terms that describe people whose gender identity, expression and/or presentation do not conform with the gender assigned to them at birth (Pearce, Moon, Gupta, \& Steinberg, 2019). Trans and non-binary are also collective identities and movements with a political stance (Feinberg, 1998), visibilizing and critiquing the gender binary as one of the main oppressive systems of 
power in the organization of our social and sexual lives. Naturalizing the existence of only two genders (men and women), two types of bodies, two genital morphologies (penis and vagina), this binary allocates individuals into one of these two supposedly opposite genders on the basis of the supposed linear connection between sex, body, and gender. This binary norm strongly impacts sexuality, sexual imageries, and sexual encounters, and transgender sexual cultures often critically examine this binary (Bauer, 2018). A DIY sex-toy workshop thus suitably illustrates the potential of the trans and non-binary movements' organizing around sexuality to critique normative discourses of sex, sexuality, and gender.

The trans-led activist group that organized the festival works locally to create greater recognition and visibility for transgender people and culture by organizing, among others, lectures, educational programs, and cultural and social activities. The free festival's aim included workshops, film screenings, debates, and presentations touching upon sexuality and gender, and the variety within, and beyond, these categories and identities. The festival's activists, who identified as transgender, non-binary, and cisgender (people who identify with the gender assigned to them at birth), discussed topics such as sex, kinky practices, relationships, and desires, and celebrated the 'chaos' of gender identities and experiences. The objective of the festival workshop on DIY sex toys was to create a space for discussion on sexuality which would not only include but centre the voices of people with trans, non-binary, and queer experiences.

Since the activists who put together the workshop were organizing within the trans, non-binary and queer social movement, my first expectation is that they would stimulate a counter-discourse on sexuality as a reaction to mainstream society's lack of socio-cultural imagery around sexuality that is produced by and for trans and non-binary people. As an alternative to the cis-heteropatriarchal discourse, this counter-discourse would allow trans and non-binary people to recognize themselves and to be recognized as desiring and desirable subjects (Salamon, 2010).

Secondly, as this workshop produced sex toys through not-for-profit and DIY principles, I expect that it would also attempt to break the sex toys and sexuality's dependency on the market-or at least that there might be opposition to this dependence, to sex toys as commodities, and by extension to the commodification of sex, sexuality, and the body. This is in line with the ways in which DIY is described in sociopolitical studies, namely as an ethos typically associated with underground scenes (Pearce \& Lohman, 2019), countercultures, and their communities (Hemphill \& Leskowitz, 2013).

Scholars in sexuality and organization studies have highlighted the centrality of sexuality in organizational (power) relations, and the ways in which sexuality is in/visibilized, controlled, violently exercised, normativized, and/or resisted in 'non-sexual' workplaces and business environments (Hearn \& Parkin, 2001), as well as in the sex industries and sex work (Brewis, Tyler, \& Mills, 2014). Scholars such as O'Shea (2018b) and Thanem and Wallenberg (2016) have highlighted the political relevance of embodied transgender experiences and situated trans perspectives in organizations, and in studies of gender, sexuality and organization in the ways in which they question the sex/gender binary as a normative-although often assumed-organizing principle. Nonetheless, empirical research focusing on socialmovement organizing to create political change in trans and non-binary sexual cultures remains scant (Aaltio \& Mills, 2003). I argue that these modes of organizing, which I call 'trans-organizing,' problematize, resist, (re)produce, and counter-produce sexuality politics, discourses, and practices in an attempt to 'dis/organize' the normative binary sex/gender onto-epistemology that underpins organizational spaces. Since, at present, the literature does not articulate how this dis/organizing happens, I will use this article to ask: How does transorganizing around sexuality displace the gender binary? In order to answer my research question, I conducted an exploratory qualitative case study in the context of a DIY sex-toy workshop. In so doing, I contribute to the field of sexuality and organization by bringing the concept of 'trans-organizing' into extant understandings of sexuality, organization, and political change, and by showing the (organizational) processes through which a 'dis/organization' of the normative binary materializes in trans-organizing around sexuality. Though the processes that emerge from my case study are not exhaustive, they are illustrative of the forms that trans-organizing might take and the (political) processes that might materialize. And this article wishes to encourage further research on the topic of trans-organizing and political change in organization studies.

After explaining my theoretical framework, I will discuss my methodology and findings, ending with a conclusion. My theoretical framework draws from social-movement, transgender, and organization studies to develop my conceptual lens. My own concept of 'trans-organizing' is key here, as it denotes a specific mode of dis/organization that problematizes the binary sex/gender, dis-orienting and re-orienting organizational discourses and practices around an alternative onto-epistemology. In my methodology section, I discuss my qualitative research approach to fieldwork (sample, data collection, recruitment, and analysis), particularly also the implications of the relationship between activism-research, and my own positionality as a trans activist and researcher in the field (Rooke, 2010). My findings show at least three processes through which trans-organizing around sexuality displaces the gender binary: dis/organizing 1) language; 2) embodiment; and 3) knowledge sharing. I conclude by explaining how transorganizing (around sexuality) recognizes an alternative onto-epistemology from a trans perspective through an emerging process. 


\section{Theoretical Framework}

Scholars working on trans issues and organization have highlighted the complex and contradictory ways in which transgender experiences often trouble organizations, particularly by visibilizing the sex/gender binary as a pervasive norm (Muhr, Sullivan, \& Rich, 2016; O'Shea, 2018b; Thanem \& Wallenberg, 2016). However, little is known, on what the effects of a trans perspective on organizing might be. I will draw up my 'trans-organizing' concept out of a multidisciplinary dialogue: 1) I first use the notion of 'problematicity' rooted in social-movement studies, which helps me to capture trans-organizing's political/oppositional dimension in a situated context; 2) next I take up Thanem's (2001) critique regarding the absence of the body in organizational perspectives on dis/organization and reference transgender studies to discuss 'dis-orientation' and 're-orientation' as organizational lenses that help us understand which norms transorganizing displaces and then redirects, as well as how and in relation to which embodied lives; and 3) in the third section, I then bring the notion of 'formativeness' to understandings of trans-organizing as an emerging alternative onto-epistemology.

\subsection{A DIY Sex-Toy Workshop as a Social Movement Organization}

I conceptualize the DIY sex-toy workshop as a type of social movement organization (SMO), a complex and dynamic organization that is expressly affiliated with an oppositional movement and tries to implement its objectives (McCarthy \& Zald, 1977). Affiliated with the trans and non-binary movement, the workshop implements a critique of the gender binary. The workshop's aim is not to make direct claims to the State (to change institutional structures, for instance), but rather to create a safe, temporary crafting space to develop utopian visions for the future. This form of trans-organizing materializes a sort of 'transgressive contention,' rather than 'prescribed politics.' Since trans-organizing mobilizes efforts towards change that require the conscious, contingent, and continuous mobilization of both people that identify as trans and/or non-binary as well as people who do not, we cannot understand trans-organizing through a conceptual emphasis on organizational structures. Instead, we need to focus on organizing as a process, specifically as a process of dis/organization. Resources are mobilized with the aim of 1) making visible the dominant gender binary as a system of power and oppression, and 2) disorienting and re-orienting the ways in which it materializes in favour of an alternative that centres trans and nonbinary perspectives. Since this political dis/organization is neither permanent nor long-term, it requires resources to be mobilized continuously.

Trans-organizing is a political grassroots process that facilitates and structures collective action towards change in transgender and non-binary sexuality. Power might operate in and out of its 'dis/organization,' often unintentionally or unconventionally (Hardy, Phillips, \& Clegg, 2001). From the vantage point of trans-organizing, the body-sex-gender binary is an all-pervasive structure that influences our ideas and practices around 'organization.' Scholars such as Hatch (2018) conceptualize an 'organization' as made of spheres such as technological, social, physical, and cultural structures that overlap and influence each other in an environment they simultaneously help to shape. These spheres, and their interactions, are impacted by gendered social processes where power plays a central role. This occurs when 'organizing' involves mobilizing people and resources, (re)constructing organizational actors' purposes and identities, creating alliances, or developing ideologies and cultural frames for collective action. The (overlapping) spheres influence each other and are influenced through trans-organizing. These spheres include, among others, behaviours, bodies, perceptions, communication, imagery, and the onto-epistemological presuppositions that link them. My focus for this reason is not on macromovements, as typical in SMO analysis, but on microorganizational processes.

In analysing these micro-organizational processes, I use the notion of 'problematicity' (McCright \& Dunlap, 2011), defined as the degree to which something is framed as problematic. It helps us understand what trans-organizing is questioning. Moreover, it sheds light on how trans-organizing limns that problematicity. Since trans-organizing develops in a socio-cultural context where power dynamics invisibilize trans and non-binary experiences of sexuality, deny their attendant sexual imageries, and justify violence and discrimination towards trans and non-binary people through and across sexuality, it aims to create a space that is not only alternative but also 'protected' in opposition to and in counterproduction from the dominant environment. This highlights the need to redefine/reconceptualize the interactions between organization and environment, and question their reciprocal influence as traditionally defined in organization studies. In fact, when it comes to 'trans-organizing,' this relationship is one of ontoepistemological problematization.

The notion of trans-organizing helps us reflect on how problematicity is limned and thus challenges notions around the relationships between organizers, organization, and environment. Cooper (1986) defines the relationship between organization and environment as the concomitance of order and disorder, organization and disorganization. He states that traditional ideas of organization do not involve their environment, let alone disorganization. Analysing both organization and dis/organization, order and disorder provides insight into the ways that trans activists carve out boundaries at the DIY sex-toy workshop in relation to the larger environment of the sex toy industry. However, this does not explain to what extent trans-organizing activates processes in which these boundaries are changed. In the 
next section, I take seriously Thanem's (2001) critique that most definitions of the relationship between organization and dis/organization do not consider the body and therefore remain disembodied. I will put in dialogue organization and transgender studies to discuss dis/organization in relation to trans embodiment, particularly the 'dis-orientation' and 're-orientation' of the body-sex-gender constellation (Lau, 2018). This will allow me to see trans-organizing around sexuality as a process that, after problematizing the sex/gender binary, activates a dis-orientation and a re-orientation of discourses and practices on the basis of an alternative, trans-embodied onto-epistemology.

\subsection{Cis-Normativity, Trans Embodiment, and Dis/Organizing}

Trans-organizing is always politically positioned against what scholars in transgender studies call cis-normativity. For example, Preciado (2018) has shown how the construction of sex can reaffirm the dominant cisheterosocial norms through fragmenting the body-a hetero-partition of the body, as Preciado (2018) says, through which certain organs are cut out and transformed into the 'natural' and anatomical centre of sexual and gender difference. These parts are later resignified in binary terms to constitute a 'natural' subject (man/woman) on the basis of the supposed linear nexus between the body, sex, and gender (Butler, 2011). This also affects discourses and practices around sexuality. As Bauer (2018) notes, sexual encounters are traditionally organized through the concept that bodies have a certain sex (a 'natural' genital morphology-vagina or penis), and that gender and desire are based on the type of sex and body. On the one hand, the trans experience remains subject to this cis-normative nexus. To talk about sexuality in relation to, and in intersection with, trans experiences is in itself a marginalized and rarely empowering operation, stigmatized and stigmatizing (Kondelin, 2014). The dominant narrative depicts trans as a sexual dysfunction or pathology rather than a gender experience (Pignedoli, 2017) and hyper-sexualizes and/or fetishizes trans people, particularly trans women and transfeminine people, which transgender, feminist, and transfeminist scholars flag as a transphobic and transmisogynistic response (Serrano, 2007).

On the other hand, the trans experience has the potential to expose the binary norm as exercising a dominant socio-cultural control over bodies and practices and as privileging a cisgender perspective. As I argued in one of my conference papers (Virtù, 2017), this nexus influences not just the discourses around sexualized and gendered subjects, but also the organizational processes around sexuality in a capitalist/commercial setting. Describing my experience as a gender-nonconforming trans researcher in the field of business sex-toy fairs, I showed how my body-sexgender was non-existent in the cis-normative eyes of the business people at these fairs: my sex was always assumed in a binary way, and I was either offered correspondingly penis-oriented or vagina-oriented sex toys with explicit sexed/gendered marketing.

Scholars in transgender studies have developed several reflections that displace the cis-normative ontoepistemology around the body-sex-gender and propose alternative ways of conceptualizing the body, based primarily on the lived and indeed embodied experiences of trans and gender-variant people: corporeality in relation to self-identification (Salamon, 2010); sexuality, trans materiality, and expanding the boundaries between the body and its 'environment' (Bauer, 2018); self-reflexivity and the question of non-binary im/possibility and violence (O'Shea, 2018a); and dis-orientation and trans experience as de-creation (Lau, 2018). These conceptualizations show the ways we conceive the onto-epistemology of sex and its interaction with gender and sexuality, is what produces trans bodies and identities, constructed at the intersection of multiple discourses and sociocultural practices, involving control, negotiation, counterproduction, and resistance networks (Stryker \& Whittle, 2006). Moreover, as shown by the more recent stream in sexuality and organization studies (Brewis et al., 2014), sexuality is highly organized and organizing. This field has produced studies on the dynamics of power and the cishetero-patriarchal norms that materialize within organizational spaces and workplaces, among others the exclusion/inclusion/capitalization of lesbian and gay identities in the production of value (Burchiellaro, 2019), the specificities of sex work as work, and gender violence and sexual harassment in the workplace (Brewis \& Linstead, 2000). However, little attention has been given to the ways in which onto-epistemologies of sex are (re)produced, resisted, or challenged in organizations that promote a cultural change around sexuality, let alone from a trans perspective. These organizations, often informal collectives and non-profit associations with an activist bent, are rarely taken seriously either theoretically or empirically, perhaps because the organizational processes in these contexts tend to be more volatile compared to more formalized organizational processes.

In this sense, trans-organizing takes seriously dis/organization as a process that blurs the static division between organization and environment, and dis-orients and re-orients these boundaries starting from a selfreflection both around the cis-normative ideas about the body and alternative trans embodiments. I have put dis-organization, 'dis-orienting,' and 're-orienting' in dialogue in order to understand the ways in which transorganizing develops an alternative onto-epistemology based on a trans embodied perspective, complicating the idea of static boundaries between organizers, organization, and environment by bringing embodiment into this constellation. In the next section, I will consider how trans-organizing's alternative onto-epistemology emerges as knowledge. 


\subsection{Trans-Organizing as Formative Practice}

Trans-organizing around sexuality (counter-)produces knowledge both through producing new ideas around sexuality/the body-sex-gender constellation and through its own organizational processes. It does this through what Nicolini (2016) calls 'practices.' I specifically want to highlight practices of 'formativeness,' the type of knowledge that is generated as the object of the practice is formed. Formativeness, as Gherardi and Perrotta (2013) argue, is the process by which ways of doing are discovered while activities are being performed. This perspective allows us to focus our analysis on how the different elements of a trans-organizing practice are held together, rather than on the specific elements individually. This way, we can name the emerging process through which an alternative onto-epistemology is recognized within the trans-organizing activities.

The theoretical framework delineated above helps me to unpack how trans-organizing, in the specific case of the DIY sex-toy workshop, displaces the gender binary through the organizational processes, or better dis/organizing processes, that characterize this mode of organizing (problematizing, dis-orienting and orienting, and formativeness practices).

\section{Methodology}

My methodological framework is qualitative. I conducted an exploratory case study into trans-organizing around sexuality in its lived, embodied, and contextually (politically) situated setting (Harrison, Birks, Franklin, \& Mills, 2017). The trans-led workshop on DIY sex toys is illustrative of trans-organizing around sexuality for three reasons:

1) The workshop is not unique; it is embedded in a genealogy of anti-capitalist, feminist, and queer ateliers-including sex-toy workshops-that have centred sex, sexuality, and the body in their political reflection on cis-hetero-patriarchal norms, and reclaimed technologies of sex as a political tool for community building and collective action (Borghi, 2013; Preciado, 2018).

2) The workshop was explicitly organized by trans and non-binary identified people. Due to the lack of trans visibility and the stigma around trans, sex and sexuality, few events, programs, and organizations deal with these topics systematically, and usually they are not trans-led. Ones that are tend to be grass-roots, occasional, and displaced, often involving the intimate and exclusive participation of the trans community.

3) The workshop not only addressed trans and nonbinary people, but also centred their experiences and voices in the decision-making process and the relationality within the workshop. This case study thus surfaces more than the personal experience of 'being a trans person' within an organization/in relation to sexuality, but also the processes that emerge from a trans perspective on organizing around sexuality.

The data were collected between September and October 2016 using multiple methods. First, I collected the textual and visual promotional material. These include a flyer, a poster, and the social-media listing. Then, I conducted two semi-structured interviews with the two organizers during the workshop's preparation phase. Finally, I conducted participant observation at the actual workshop, interacting with the other workshop participants as a DIY sex-toy learner/maker. The workshop lasted around 75 minutes and involved twelve participating learners/makers, excluding the two organizers. All the participants knew that I was a researcher and consented to my taking field notes during (and after) the workshop in my research diary. I collected these types of data to investigate the meanings that the lived experience of organizing around sexuality had for the trans and non-binary activists involved: 1) how they described their event to the world (flyer, poster, socialmedia listing); 2) how they imagined and constructed the workshop beforehand (interviews); and 3) their experiences organizing relationally during the workshop (participant observation).

All respondents' names used in this article are pseudonyms. My access was negotiated thanks to my involvement as a trans activist (Rooke, 2010). At the time I was active in several groups struggling for trans depathologization and promoting trans cultural production in the Netherlands and Italy. One of the festival's organizers, Sky, invited me to talk about my experience of sexuality as a trans-masculine person and told me that he was also organizing a DIY sex-toy workshop together with Hadar, a non-binary activist designing a genderless toy. Immediately interested, I asked if they would be open to me expanding my PhD fieldwork to study the organizational process of the workshop. He enthusiastically agreed and put me in touch with Hadar, who also loved the idea. It was thus not just me as a researcher 'selecting' the field, but also the 'field' approaching me as a trans activist and researcher.

I analysed my data through Critical Discourse Analysis (CDA), which helps to understand the complex narrative that emerges from the data as a socio-political practice (Thurlow, 2016). Moreover, it surfaces this narrative in (counter)dialogue-both in what is and is not saidwith normative and non-normative discourses of sexuality and organization. I conducted the interviews separately, in places of their choice, and in English (not our mother-tongue, but the language we used to communicate, also during the workshop). I assured the interviewees I would be the only one with access to the anonymized transcripts. The interviews' guiding topics were: their reason for organizing the workshop, how their personal experiences of sexuality affected their 
organization of the workshop, how they imagined its setting, and what knowledge the workshop required. I also gave space to topics that spontaneously emerged. I coded the interviews, promotional materials, and fieldnotes in a continuous mutual adjustment between the data and the theoretical framework. My sensitizing concepts in the analysis were: 'problematicity,' 'dis-orienting and re-orienting,' and 'formativeness practices' in relation to the sex/gender binary.

\section{Findings}

In this section I analyse the DIY sex-toy workshop, particularly three of its dis/organizing processes that displace the normative gender binary: 1) dis/organizing language; 2) dis/organizing embodiment; and 3) dis/organizing knowledge sharing.

\subsection{Dis/Organizing Language: Complicating Identities and Ungendering Objects}

The activists I interviewed are very attentive to language in their organizational processes. They proposed we first reflect on how people are talked about. When the organizers address the potential participants, they do so recognizing the problematicity of binary labels when addressing the topic of sexuality. The flyer promoting the event read: "When we try to put clear labels on people a lot gets lost. Between man and woman, between straight and gay, between sexual and asexual, between all labels there is space, the space of...well, of everything else." This text clearly problematizes 'naturalized' processes of categorizing people, particularly three types of binary categories: gender identity, sexual orientation, and desire. Imposing such fixed categories limits the complexity and variety of possible identities and experiences in relation to, respectively, gender, sexual orientation, and the very same idea of necessarily 'being' either sexual or asexual. However much it is intended to make the world intelligible, labelling people implies a loss: many, whether they feel connected to these binary categories or excluded by/from them, instead experience a range (what has been defined as a 'spectrum') of sexual orientations and desires. The flyer acknowledges this as real and valid, 'as the space of everything else.'

The front of the flyer (not included here so as not risk the participants' anonymity) shows several terms nestled within an open fan-shaped drawing, terms like 'trans,' 'transgender,' 'transsexual,' 'mtf,' 'ftm,' 'intersex,' 'kinky,' and 'questioning.' This signals a spectrum of nonconforming identities and experiences in relation to traditional 'naturalized' sexuality discourses, and therefore explicitly addresses the multiple non-normative (and often political) identities and experiences of potential participants who do not fit the binary gender norm. A disorientation of binary categories emerges, also concerning the target audience: the event, although not exclusive, gives priority to trans and non-binary experiences.
In the interview, talking about how he imagines the workshop space, Sky said:

The workshop is addressed to anyone, anyone who wants to make sex toys, but specifically people of non-binary experience who want to make sex toys, or who can't afford sex toys or who want vegan sex toys. That's our three main audiences, people with non-binary experiences, non-standard bodies, vegans, and people who can't afford sex toys. Obviously, there might be people who don't fit any of these three groups and still want to come to the workshop....Our aim is to address the topics that most organizations are afraid to talk about because it might damage their reputation if they talk too much about kink or about sex or about the nitty-gritty of messy gender identities. Too much of a radical point of view to address.

By broadening the language around what subjects get to be 'named' and prioritizing subjects who are usually invisible in organizations, the organizers dis-orient assumptions around who traditionally fits and who does not, who is assumed to exist in events around sexuality and who is not.

As we read in the flyer, anyone is invited to the event if they wish to "discover the versatility and fluidity of sexuality, gender, desire, fantasy, appearance, personality, body, and identity," to explore "a space beyond labels." The organizers thus do not just address those experiences that are marginalized and silenced, but make it clear that they wish to collectively explore a utopian space beyond categories and categorizations. It is this utopia that Hadar addressed in our interview when they imagine their interaction with workshop participants:

I keep thinking, is there something that I will ask the cast models? To define themselves? Or is it just...do you need those words or not? It's a very good question, I don't know. I think it is very much up to them if they feel that's a flag they want to put in front of them and say "I am transgender," or "I am this." Specifically the people that I engage with are so special and so unique that they defy-for me at least, that's why I love them - they just defy any simple category, and for me that's what I am interested in....I do like the word queer because it fucking means nothing! It just means "don't put me in a box," at least for me. But on the other hand I know, and this I know more from my political activism, that when you are actually being oppressed-which a lot of this community is, there is no doubt-then flags do help, they unite you, they make you feel strong, and you can sort of present to the other side.

Starting from an ontology of uniqueness and a defiance of the binary's 'simplicity,' Hadar still recognizes the political (collective and individual) importance of 
self-definition. The organizers suggest re-orienting the categorization process towards self-reflexivity and selfdetermination, reflecting on one's own ontology while recognizing other people's reasoning.

This dis/organizing process also emerges in the ways objects are talked about in the production of DIY sex toys. When Sky imagined how he will present the sex toys in the workshop, he said:

A very simple base-line is I am never ever going to go like "this is a toy for trans men" or "this is a toy for trans women," or "this is a toy for women" or "this is a toy for men." But more like "this is this toy and it might work for some bodies and it might not work for others. This might be more effective for people with either a large clitoris or a penis, or whatever, but it might work for you even if you don't have that."

What emerges here is the problematization of categorizing objects in terms of their fit with a binary gender identity. Instead, the object is described in tentative terms that refer to a materiality of bodies that is not based on gendered categories. The organizers propose dis-orienting the ways we tend to connect sex toys to gender identity (conforming and non-conforming) and the materiality of the body towards a practice of 'ungendering.' During the interview, Sky continued:

So I am going to try not to gender sex toys, and I am going to try to address specifically ungendering things that are usually gendered. I don't gender stuff like dildos and penises as male...and anal stuff is totally genderless: We've all got an ass. I am trying to ungender sex and sex toys, there is no need for gender to be in there unless you specifically want to put it in there, unless it's hot for you.

This dis-orienting practice of ungendering concerns the object, but it is also a mediated operation that the organizers use to take for granted neither the participants' identities nor their 'corporealities' (Salamon, 2010). Ungendering objects allows for re-orienting the relationship between gender identity, gender experiences, and the object towards one of self-determination: a formativeness practice that allows people, in particular trans and non-binary people, to live and share the full range of 'corporealities' and 'identifications' through an often changing and contextual re-genderization that is not imposed but that emerges from their own desires.

\subsection{Dis/Organizing Embodiment: Unknown Bodies and Formative Pleasures}

The activists involved in organizing the DIY sex-toy workshop recognize the lack of attention to trans and nonbinary communities in the mainstream production and dissemination of sex toys, as Sky explained:
I was interested in doing a make-your-own-sex-toy workshop because I noticed that transgender people mostly do not have access to sex toys that meet their needs and even the ones that are out there are very narrow, focusing either on non-transitioning transgender people or on one idea of what they think transitioned people are like, when a lot of people have bodies somewhere in-between. I think that [in queer feminist sex-toy shops] there is some awareness of trans people, but they are very often assumed to have certain bodies, they are for instance either assumed to be trans men with no surgery at all...or trans women with no bottom surgery at all. So they are basically adapting a technique that already exists for cis men and cis women to be less gendered in order to fit trans bodies more.

The organizers problematize an imagery based on a cisnormative epistemology that excludes the full variety of trans bodies. A cis-normative epistemology assumes how trans bodies are constituted as sexual according to a cisgender framework (Bauer, 2018). What emerges is a critique to the limited set of ideas about trans bodies in the dominant sex-toy industry culture, which sets nontransitioning trans and non-binary bodies within a cisgender framework, and maintains stereotypical ideas of how trans and non-binary bodies should be after people have gone through transitioning. Sky continued:

I haven't seen much that really considers crosssurgery trans results and post-hormones trans results, like a trans man with a lot of clitoris growth or a trans woman with a changing penis; toys that address that some trans bodies are different. There is no trans-man sex toy that addresses people with a metoidioplasty, and there's hardly any sex toy that address the specific function and sensitivity of a phalloplasty. And if there are no sex toys [that] appeal to you, that fit your body, you gotta DIY. If you can learn to make sex toys...yourself, you can adapt it to any body you have.

Here, the binary imagery around (trans and non-binary) bodies is dis-oriented by acknowledging the variety of trans materialities and corporealities: in fact, a lot of people have bodies in-between. The organizers dis-orient the linear body-sex-gender nexus (Preciado, 2018), clearly showing that the parts/technologies of the body constructed as 'sex' are various and modifiable, just like their attendant desires and pleasures. For instance, Sky notes the technologies of the body that are often (but not always) part of a wished/wanted transitioning process. Often, these processes have a material impact on the body, the morphology, and the pleasures of trans people. Sky openly discussed these stigmatized technologies and unknown (un)pleasures, which are rarely talked about:

When I noticed that sex toys for my body type didn't exist, I looked for weird-shaped sex toys to see if 
there was anything that accidentally fit my body. I found one in the shape of a spaceship and...one that was more like a triangle and then some other weird shapes. Anyway, they were not that effective. Right now, I don't really know anything that works perfectly for my body and for my partners' bodies-anyway, I noticed that some were effective accidentally, but they weren't designed for my body.

I don't have solutions for every type of body, I can say some stuff like, "this works on my kind of body," but I don't have all the solutions, I am more thinking that if you have the skills, if you can make your own sex toys, you can adapt it to your own situation, and it's more about getting started on making stuff and realizing that you can do it yourself, and ideally I would also like to work with making your own vibrating toys-still working on that to make that safe and practical in a workshop. And after that you can invent the shape, if you can use silicon you can make any shape you want, if you use rubber and little vibrating instruments you can be creative. And you can see what works for your body...and not say, "well this is my answer to the metaphalloplasty," 'cause it will not fit every person. I don't have all the answers yet but I am trying to teach people how to get creative making sex toys that meet non-standard bodies, even if I am really struggling to do that myself.

He makes specific reference to some trans-masculine embodiments: because of hormones, but also due to surgical processes such as metoidioplasty or phalloplasty, the bodies of trans men and of trans-masculine people who follow this path develop and acquire specific functions and sensitivities. What emerges is a re-orientation towards a situated, embodied reflection on trans materialities, their changing spectrum, and their relationship to pleasure. DIY makes it possible for trans people to examine and address these specificities, and thus recognize the diversity of trans bodies, the spectrum of trans corporealities. DIY sex toys thus become a formativeness practice (Gherardi \& Perrotta, 2013), a way to know and to recognize an alternative corporeality at the very same time as the object is negotiated.

Hadar proposed another re-orientation:

There are not many people that I think can identify with my weird sexuality! And this-making your own sex toys in a workshop-is definitely a good way to sort of find them and connect and talk about these things, and I guess to explore a special non-binary imagination. Especially for people that aren't going through hormone therapy and surgeries, imagination is basically a very good tool that you have and it has been very useful for me, sort of realizing that your imagination is boundless, and your brain can sense and feel this imagination.
It is clear that DIY is a process of becoming, an emerging process in which the epistemological linearity of body-sex-gender is problematized, dis-oriented, and reoriented towards a situated, embodied reflection on the variety of trans materiality and non-binary imagination. It is not about producing objects for bodies (and their attendant needs) that are already given and/or known within cis-normativity; it is a tentative process of knowing of one's own trans embodiment, one's own pleasures, that emerges in and through the very same DIY practice: to make your own sex toys so that your trans body becomes the starting point from which to limn your organizational knowledge (Thanem, 2001), and in fact to re/discover the sensitivities of your body through DIY production.

\subsection{Dis/Organizing Knowledge Sharing: Vulnerability as Method, Creating Safer Spaces}

As the organizers are very aware that traditional learning patterns are influenced by normative structures of power, DIY becomes a political practice of empowerment, also in the ideation of DIY sex toys. Hadar explained: "[W]e think 'oh wow, things are so hard to make,' but you know?....Seriously, a lot of this is patriarchy." They continued:

You know, as a kid you believe in a lot of this, "I can't do that; I am not stable enough; I am not focused enough; I can't," and then you just learn that that's not true. You might need to practice a few times, destroy a few of your prototypes, but you can learn how to do just about anything.

In the experience of my interviewees, the DIY learning process is key, not only personally but also organizationally. Sky explained:

My intention is mostly to say, "look, I am not perfect, I am no expert, I read some zines about it, I tried a few things, and let's move from the starting point to this workshop, not as much a teacher-student relationship, as a let's-learn-together relationship."

Along with this refusal of traditional hierarchies in the learning process, which often occurs in social-movement organizations (Hemphill \& Leskowitz, 2013), it is interesting how these activists are more concerned about being perceived as assuming positions of authority, than about being exposed to any stigmatization due to their non-normative trans and non-binary experiences. As Sky explained:

People are so used to authoritative workshops where one person has all the knowledge, and I love, you know, non-hierarchical workshops based on sharing and learning together. 
I am not worried about talking about my sex life. I am slightly worried about being seen as an authority on the topic, even though I am not an expert at all. So I am just going to have to stress at the beginning that I am still learning, everybody is here to learn, and let's try to cooperate. I hope people understand that and do not get disappointed when I don't have all the answers.

The search for, and implementation of, an alternative learning methodology is a work in progress linked to the desire to create an environment that is 'protected' and safe for the people involved, as Sky said:

There's several approaches to achieving [a safe space]. My most common approach is personal vulnerability: If I am very open about my sex life and about my situation, more open than they are used to, that usually creates that space.

This alternative methodology is particularly activated through reference to the trans experience, as became clear in my interview with Sky:

I am pretty comfortable talking about some things that other people experience as really vulnerable, for example transition and coming out as transgender to cis people. They often experience it as an extremely vulnerable thing, so if I come out of the closet and talk about being transgender and talk about transitioning, this helps them in talking about something that they feel vulnerable about, and I kind of learned to use that as a social technique, creating space for shame and vulnerability and insecurity by trying to be the most vulnerable person in the room.

Here, the trans experience becomes the very tool that makes the alternative learning process possible: Personal vulnerability becomes the method.

\section{Conclusion}

In my introduction I defined trans-organizing as a set of dis/organizing processes that materialize through the contingent and continuous practice of problematizing the gender binary, and dis-orienting and re-orienting organizational discourses and practices around an alternative onto-epistemology. My findings in the context of a trans-led DIY workshop hint at three key transorganizing processes.

Firstly, dis/organizing language around sexuality means to problematize the 'naturality' of categorizing people and objects according to a binary logic in order to achieve a supposed intelligibility. In trans-organizing, binary categories are dis-oriented through the explicit mentioning of multiple non-normative and political identities, and re-oriented (in a contingent and continuous way) towards self-reflexivity and self-determination. In the case of the DIY sex toy workshop, trans-organizing means dis-orienting the binary connections between sex objects and 'gender identity' through practices of ungendering, and re-orienting them towards a contingent and continuous re-genderization that emerges from desire.

Secondly, dis/organizing embodiment around sexuality means to problematize the ways in which imageries around the materiality of the body are constructed upon a binary logic, a cis-normative epistemology of embodiment. In trans-organizing the 'naturalized' linearity bodysex-gender is dis-oriented through the acknowledgment of the variety of trans embodied materialities and their entanglement with an alternative imagery, a 'non-binary imagination.' Moreover, trans-organizing suggests a reorientation towards embodiments and pleasures as practices of formativeness, new knowledge that emerges while the practice is performed.

Thirdly, dis/organizing knowledge sharing around sexuality means to problematize the traditional teaching/learning model as influenced by normative (patriarchal) structures of power. Trans-organizing dis-orients this model through a practice of collective sharing, while re-orientating towards an affective methodology of the margins.

To conclude, trans-organizing (around sexuality) constitutes the process through which an alternative (sex/gender) onto-epistemology is recognized from a trans perspective at the very same time in which the activities of trans-organizing take place, namely in an emerging process. The required safe spaces are not created from a reciprocal influence between the organization and the external environment, but emerge from a political process that shapes this alternative onto-epistemology of sexuality centring the variety and contradictions of situated trans and non-binary voices and experiences.

\section{Acknowledgments}

My utmost gratitude goes to the research respondents who generously shared their time, trust, knowledge and experience of activism with me.

\section{Conflict of Interests}

The author declares no conflict of interests.

\section{References}

Aaltio, I., \& Mills, A. J. (Eds.). (2003). Gender, identity and the culture of organizations. London and New York, NY: Routledge.

Bauer, R. (2018). Cybercocks and holodicks: Renegotiating the boundaries of material embodiment in les-bitrans-queer BDSM practices. Graduate Journal of Social Science, 14(2), 58-82.

Borghi, R. (2013). Post-porn. Rue Descartes, 79(3), 29-41. Brewis, J., \& Linstead, S. (2000). Sex, work and sex work: 
Eroticizing organization. London and New York, NY: Routledge.

Brewis, J., Tyler, M., \& Mills, A. (2014). Sexuality and organizational analysis -30 years on: Editorial introduction. Organization, 21(3), 305-311.

Burchiellaro, O. (2019). LGBT-friendliness \& the promise of inclusion: A queering ethnography of inclusion in the 'diversity world' of business and the social world of 'queer activism' in London (Doctoral dissertation). University of Westminster, London, UK.

Butler, J. (2011). Bodies that matter: On the discursive limits of sex. New York, NY: Routledge.

Comella, L. (2017). Vibrator nation: How feminist sex-toy stores changed the business of pleasure. Durham and London: Duke University Press.

Cooper, R. (1986). Organization/disorganization. Information (International Social Science Council), 25(2), 299-335.

Feinberg, L. (1998). Trans liberation: Beyond pink or blue. Boston, MA: Beacon Press.

Gherardi, S., \& Perrotta, M. (2013). Doing by inventing the way of doing: Formativeness as the linkage of meaning and matter. In P. R. Carlile, D. Nicolini, A. Langley, \& H. Tsoukas (Eds.), How matter matters: Objects, artifacts and materiality in organization studies (pp. 227-259). Oxford: Oxford University Press.

Hardy, C., Phillips, N., \& Clegg, S. (2001). Reflexivity in organization and management theory: A study of the production of the research subject. Human Relations, 54(5), 531-560.

Harrison, H., Birks, M., Franklin, R., \& Mills, J. (2017). Case study research: Foundations and methodological orientations. Forum: Qualitative Social Research, 18(1), 1-17.

Hatch, M. J. (2018). Organization theory: Modern, symbolic, and postmodern perspectives. Oxford: Oxford University Press.

Hearn, J., \& Parkin, W. (2001). Gender, sexuality and violence in organizations: The unspoken forces of organization violations. London: Sage.

Hemphill, D., \& Leskowitz, S. (2013). DIY activists: Communities of practice, cultural dialogism, and radical knowledge sharing. Adult Education Quarterly, 63(1), 57-77.

Kondelin, S. (2014). Dis/orientations of gender and sexuality in transgender embodiment. SQS Journal, 8(1/2), 32-43.

Lau, J. R. (2018). Transition as decreation: A transfeminist phenomenology of mixed/queer orientation. Graduate Journal of Social Science, 14(2), 24-43.

McCarthy, J. D., \& Zald, M. N. (1977). Resource mobilization and social movements: A partial theory. American Journal of Sociology, 82(6), 1212-1241.

McCaughey, M., \& French, C. (2001). Women's sex-toy parties: Technology, orgasm, and commodification. Sexuality and Culture, 5(3), 77-96.

McCright, A. M., \& Dunlap, R. E. (2011). Cool dudes: The denial of climate change among conservative white males in the United States. Global Environmental Change, 21(4), 1163-1172.

Muhr, S. L., Sullivan, K. R., \& Rich, C. (2016). Situated transgressiveness: Exploring one transwoman's lived experiences across three situated contexts. Gender, Work \& Organization, 23(1), 52-70.

Nicolini, D. (2016). Knowing in organizations: A practicebased approach. New York, NY: Routledge.

O'Shea, S. C. (2018a). Past caring about passing. Graduate Journal of Social Science, 14(2), 47-57.

O'Shea, S. C. (2018b). This girl's life: An autoethnography. Organization, 25(1), 3-20.

Pearce, R., \& Lohman, K. (2019). De/constructing DIY identities in a trans music scene. Sexualities, 22(1/2), 97-113.

Pearce, R., Moon, I., Gupta, K., \& Steinberg, D. L. (2019). The emergence of trans: Cultures, politics and everyday lives. Oxon and New York, NY: Routledge.

Pignedoli, C. (2017). Beyond trans medicalization: Gatekeeping and the epistemological privilege of ignorance. Paper presented at the Centro Interuniversitario di Ricerca Queer Conference, L'Aquila, Italia.

Preciado, P. B. (2018). Countersexual manifesto. New York, NY: Columbia University Press.

Rooke, A. (2010). Queer in the field: On emotions, temporality and performativity in ethnography. In $\mathrm{K}$. Browne \& K. J. Nash (Eds.), Queer methods and methodologies: Intersecting queer theories and social science research (pp. 25-41). Farnahm: Ashgate.

Salamon, G. (2010). Assuming a body: Transgender and rhetoric of materiality. New York, NY: Columbia University Press.

Serrano, J. (2007). Whipping girl: A transsexual woman on sexism and the scapegoating of femininity. Berkeley, CA: Seal Press.

Stryker, S., \& Whittle, S. (Eds.). (2006). The transgender studies reader. New York, NY: Routledge.

Thanem, T. (2001). Processing the body: A comment on Cooper. Ephemera: Critical Dialogues on Organization, 1(4), 348-366.

Thanem, T., \& Wallenberg, L. (2016). Just doing gender? Transvestism and the power of underdoing gender in everyday life and work. Organization, 23(2), 250-271.

Thurlow, C. (2016). Queering critical discourse studies or/and performing 'post-class' ideologies. Critical Discourse Studies, 13(5), 485-514.

Tyler, M. (2004). Managing between the sheets: Lifestyle magazines and the management of sexuality in everyday life. Sexualities, 7(1), 81-106.

Tyler, M. (2011). Tainted love: From dirty work to abject labour in Soho's sex shops. Human Relations, 64(11), 1477-1500.

Virtù, L. V. (2017). A self-reflexive approach to trans embodiment in the context of a sex toy fair. Paper presented at the Centro Interuniversitario di Ricerca Queer Conference, L’Aquila, Italia. 


\section{About the Author}

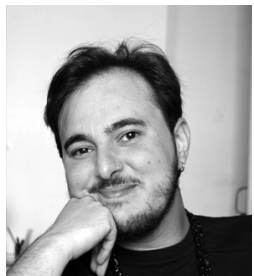

Ludovico V. Virtù is a precarious Researcher and a trans activist. With a background in comparative literature and cultural economics, he is currently a PhD Candidate in Organization Studies (Radboud University). In Italy, where he lives, he collaborates with several collectives, cultural projects and organizations on issues of transfeminist knowledge production. Among his latest publications is the special issue "Trans materialities" published in the Graduate Journal of Social Science (co-edited with Max van Midde and Olga Cielemęcka). 